\title{
Terrorism and mental illness: a pragmatic approach for the clinician $^{\dagger}$
}

\author{
Cyrus S.H. Ho, Tian Ci Quek, Roger C.M. Ho \& Carol C. Choo
}

\begin{abstract}
SUMMARY
Terrorism is a complex problem that is highly relevant in contemporary society, underscoring the need for greater understanding as well as crossdisciplinary and international research in this area. Controversies surround potential associations between mental illness and terrorism, many due to the limited and conflicting existing research, and mental health professionals' duties to their patients versus society and the state. In this article, we review the literature, discuss clinical implications and the role of psychiatrists in anti-terrorism efforts. We also propose a simplified framework that may be incorporated into clinical practice to screen for potential terrorist tendencies.
\end{abstract}

\section{LEARNING OBJECTIVES}

- Understand the landscape and recent advances in the research of terrorism

- Appreciate the importance and role of mental health professionals in preventing patients from engaging in terrorist activities

- Understand how to assess risk of patients engaging in terrorist activities

\section{DECLARATION OF INTEREST}

None.

\section{Keywords}

Terrorism; mental illness; clinical implications; clinical framework.

The term 'terrorism' was first used to describe the violent and intimidating actions of the Jacobin Club during the Reign of Terror (la Terreur) in the French Revolution. Terrorism has its roots in resistance and political movements, when people realised that force or threats could potentially compel groups towards particular agendas. Terrorism has been defined by the US Federal Bureau of Investigation (FBI) as 'the unlawful use of force or violence against persons or property to intimidate or coerce a government, the civilian population, or any segment thereof, in furtherance of political or social objectives' (Seger 2003: p. 257). There has been a rise in public attention to terrorism, with recent media coverage of high-profile incidents in the UK and Europe, including the Carcassone and Trèbes attacks in France in March 2018 and the Manchester Arena bombing in 2017.

Data published on the National Consortium for the Study of Terrorism and Responses to Terrorism's Global Terrorism Database (https://www.start. umd.edu/gtd/) reveal that, there has been an exponential increase in number of global terrorismrelated incidents, from 1907 incidents in 2001 to 13488 in 2016, and the number continues to rise. The number of deaths from terrorism-related attacks also increased, from 7743 in 2001 to 34676 in 2016. However, a study by Smith \& Zeigler (2017) pointed out that, apart from countries embroiled in civil wars, terrorism incidents since the attacks in the USA in 2001 (the ' $9 / 11$ attacks') had in fact decreased in absolute terms. The authors attributed this reduction to robust counterterrorism measures enacted by various countries worldwide after $9 / 11$, and they argued that the mainstream consensus of rise in the terrorist threat since $9 / 11$ is due to implicit negative bias in the manner that terrorist news has been reported. Headlines in the media might easily provoke the public's reaction, increasing their sense of threat (Gadarian 2010). Nevertheless, the authors warned against trivialising the threat of terrorism, a warning with which we concur. Terrorist behaviour results in public fear, insecurity and distress that have lasting detrimental effects on both physical and psychological health, and it remains a relevant and timely topic in the current landscape.

\section{Differences between terrorism and homicide}

In this article, we focus our discussion on terrorism. However, people have often questioned the association between terrorism and homicide, especially when both involve ruthless killing of people. There are intricate differences between the two and it is worthwhile clarifying these. The main distinguishing characteristic was highlighted by LaFree et al
Cyrus S.H. Ho, MRCPsych, is a consultant consultation-liaison psychiatrist in the Department of Psychological Medicine at the National University Hospital, Singapore. Tian Ci Quek is a medical student at the Yong Loo Lin School of Medicine, National University of Singapore, Singapore. Roger C.M. Ho, FRCPC, is an associate professor and senior consultant psychiatrist in the Department of Psychological Medicine at the National University of Singapore, Singapore. Carol C. Choo, DClinPsy, is associate professor in Clinical Psychology at James Cook University Singapore.

Correspondence Dr Cyrus S.H. Ho Department of Psychological Medicine, Yong Loo Lin School of Medicine, National University of Singapore, 5 Lower Kent Ridge Road, Singapore 119074. Email: su_hui_ho@nuhs.edu.sg

\section{Copyright and usage}

(C) The Royal College of Psychiatrists 2018

${ }^{\dagger}$ For a commentary on this article see this issue. 
(2018), who indicated that typical criminals who commit homicides are generally driven by personal gain and selfishness, whereas people who engage in terrorism are more often motivated by the furtherance of political causes and even altruism. Typical criminals often attempt to avoid detection after their act, whereas terrorists carry out their acts unabashedly and seek the largest audiences possible (Kydd 2006).

A retrospective study of 398 offenders by Liem et al (2018) aimed to elucidate the differences between European lone-actor terrorists and common homicide offenders. According to the study, compared with homicide offenders, loneactor terrorists were more likely to attack strangers (lone actors $80 \% \mathrm{v}$. homicide offenders 10\%), more likely not to have a history of substance misuse $(78.8 \%$ v. $19.3 \%)$ and more likely not to have a history of violence $(69.7 \%$ v. $41.4 \%)$. There were, however, no significant differences between the groups with regard to having a history of mental illness $(52 \%$ v. $51 \%)$. Nevertheless, it is necessary to be mindful that studies involving lone-actor terrorists, including this particular one, are limited by small sample sizes, and that in this study data on incidents were not available for all European countries; results are therefore unlikely to be generalisable to the global situation.

\section{Cyberterrorism}

Terrorism is traditionally associated with causing loss of life or inflicting physical harm on innocent civilians, but advances in technology have resulted in the emergence of new terrorist tactics in recent years, one of which is cyberterrorism. The FBI has defined cyberterrorism as a 'premeditated attack, politically motivated against information, computer systems, software and data, resulting in violence against non-combatant targets, by subnational groups or clandestine agents' (Pollitt 1997). The use of computer networks to attack critical national operations such as transportation and the economy generates immense public fear and havoc and compromises nationwide security. Cyberterrorism is an attractive opportunity for modern terrorists, in view of the anonymity of unleashing the attack, potential for massive damage, extensive psychological impact and media appeal (Weimann 2005). Research on characteristics of cyberterrorists is currently scarce and goes beyond the scope of this article. However, further research into this subtype of terrorism is urgently needed, as is study of the use of the internet to disseminate terrorists' propaganda and recruit vulnerable members of the public.

\section{Controversies surrounding terrorism and mental illness}

The debate about the causal association between mental illness and terrorism, although not novel, remains a critical one (Box 1). There is little information about how individuals are radicalised into taking up terrorist causes, which unfortunately opens up many interpretations and speculations of what fuels the behaviour. Different profiles exist among terrorists: there are group actors, who work within an organisation, and lone actors, individuals who are not linked to established terror groups; there are those who volunteer for suicide missions and those who strategically manipulate others to carry them out, thus ensuring their own survival. Some in the media and the public use words such as 'lunatic', 'mad', 'crazy' and 'monster' in speaking of these attackers, prejudicial epithets also commonly used to describe people with mental illnesses. Perhaps they are trying to make sense of the horrendous acts in terms of the fallacy that psychiatric patients are violent and aggressive. The fundamental burning question remains: surely perpetrators who commit such sadistic massacres must have a sick mind?

\section{Group-actor terrorists}

There is currently limited consensus, with inconsistent and often vexing findings in the literature

BOX 1 Controversies surrounding the association between terrorism and mental illness

Terrorists can be psychologically normal

The majority of terrorists recruited as part of a group operation have no psychopathology (Lankford 2014). They are more likely to be motivated by group and collective psychology and external factors (Stoddard 2011; Horowitz 2015).

Personality traits associated with terrorists

Paranoid, antisocial and sadomasochistic personality traits are associated with terrorists (Weatherston 2003). Suicide bombers are more likely to have dependent and avoidant or impulsive and emotionally unstable personality style (Merari 2009).

Lone-actor terrorists are more likely to be mentally ill In one study, $43 \%$ of the lone-actor terrorists had a history of mental illness, and the odds of a lone actor having a mental illness were 13.49 times higher than the odds of a group actor having a mental illness (Corner 2015). Mental disorders implicated include schizophrenia, delusional disorder, antisocial personality disorder and autism spectrum disorder, but no single disorder is associated with terrorism (Bhui 2016). 
regarding the role of mental illness in terrorism. Some researchers argue that people who work within a terror network are psychologically normal, although they have been socially indoctrinated (Lankford 2014). This is based on the 'selection effect' assumption that, to avoid potential security risks, the organisations would specifically screen out mentally disturbed individuals, who are likely to be erratic and difficult to train. In support of this assumption, analyses of suicide attackers from Asia, Africa, Europe, the Middle East and North America revealed that the majority were ordinary people who had no psychopathology (Lankford 2014). Controlled experiments, however, have demonstrated that ordinary people can be transformed into agents of violence through psychosocial brainwashing (Zimbardo 2004). There would undoubtedly be instances of people with pre-existing mental illness engaging in terrorism, but the numbers are likely to be low, as they are among those who carry out general criminal activity. Stoddard et al (2011) argued that terrorists who belong to a group act according to group and collective psychology and not on the basis of their individual psychopathology. This is illustrated particularly by suicide terrorists recruited as part of a group, who believe that they are engaging in 'martyrdom operations' and have been carefully trained to sacrifice their lives. It has been hypothesised that their beliefs are fuelled by the social pressure and heavy responsibility placed on them, which lead to their perception that withdrawal from the mission at any point would undoubtedly bring shame and humiliation. This sentiment is echoed by prominent terrorism scholar Horowitz (2015), who reiterated that suicide terrorists who belong to groups are mainly driven by geopolitical situations and religion, not personal factors.

Some researchers, however, have counter-argued that certain personality types, such as those with paranoid, antisocial or sadomasochistic predisposition, and those who are angry and bitter because of their marginality, may be drawn to the violence fostered by terrorism (Weatherston 2003). Furthermore, emotionally unstable individuals can still be strategically used to advance the cause, although limited operational information would be given to them, to minimise risks. In fact, it would make sense for terrorist organisations to employ them as disposable assets to carry out suicide attacks. A controlled comparative study by Merari et al (2009) evaluating personality types of suicide bombers and organisers of suicide bombing revealed that suicide bombers had significantly lower ego strength than organisers, and were more likely to have dependent and avoidant or impulsive and emotionally unstable personality style.

\section{Lone-actor terrorists}

Lone-actor terrorism has more often been linked to mental illness, possibly from the extrapolation that lone actors are most likely to be socially excluded and have 'odd' personalities, which can be precipitants of mental illness. A recent study by Corner $\mathcal{E}$ Gill (2015) reported that $43 \%$ of the lone actors assessed had a history of mental illness and that a lone-actor terrorist was 13.49 times more likely to have a mental illness than a group actor. Various mental disorders have been implicated, such as schizophrenia, delusional disorder, antisocial personality disorder and autism spectrum disorder, but no single disorder has been associated with terrorism (Bhui 2016). The study by Merari et al (2009) found that $40 \%$ of jailed Palestinian suicide bombers were assessed to have clinical signs of suicidal behaviour and 53.3\% had depressive tendencies.

\section{Socio-environmental and neurobiological factors}

Recent studies have revealed various socio-environmental and neurobiological factors associated with terrorist behaviour (Box 2).

\section{BOX 2 Socio-environmental and neurobio- logical factors associated with terrorist behaviour}

\section{Socio-environmental factors}

Socio-environmental risk factors that predispose a person to terrorism include (Campelo 2018):

- family dysfunction

- friendships with radicalised individuals

- unstable geopolitical environment

- societal polarisation (unequal socio-economic conditions in the country)

Neurobiological factors

Violent offenders were found to have the following (Bogerts 2018):

- decreased grey matter in the orbitofrontal and prefrontal cortex

- decreased volume of all temporolimbic structures and the posterior cingulate cortex

- reduced functional connectivity between the frontal cortex and the limbic areas, anterior insula and posterior cingulate cortex

- Structural and functional deficits in brain regions crucial for empathy and compassion, similar to those in individuals with antisocial personality disorder, have also been found (Blair 2005; Marazziti 2013). 


\section{Socio-environmental factors}

A meta-analysis of 22 studies of radicalised European youths by Campelo et al (2018) yielded a proposed model for identifying risk factors of 'radicalisation' among European adolescents and young adults. The suggested socio-environmental risk factors included: family dysfunction, friendships with radicalised individuals, unstable geopolitical environment, and societal polarisation (unequal socio-economic conditions in the country). However, one major drawback was that this analysis was based mostly on qualitative studies.

In their study of 112 radicalised people held in custody, Bazex et al (2017) found that a large proportion of radicalised youths had experienced a difficult and poorly nurturing childhood marked by prominent parental difficulties such as paternal absence and maternal depression, history of suicide attempt and disability. Campelo et al (2018) highlighted how a geopolitical event can influence radicalisation through the example of increased radicalisation following proclamation of the caliphate by the so-called Islamic State. MollerLeimkuhler (2018) posited that men may become radicalised because of their unhappiness when there is mismatch between their educational level and their employment because of economic stagnation in the country.

Women are also at risk of radicalisation and they do not vary significantly from their male counterparts in terms of individual motivations, which are usually in the context of nationalism, trauma, revenge and marginalisation (Speckhard 2007).

As for the debate regarding religion and terrorism, there is currently no evidence suggesting that religion is in itself a causative factor in terrorism. Rather, the intentional exploitation of ideologies and prohibition to accommodate alternative thought processes may fuel terrorism (Tarlow 2017).

\section{Neurobiological factors}

A recent review of structural and functional brain imaging studies in violent offenders over the past 10 years by Bogerts et al (2018) offers a glimpse into the possible neurobiological factors specific to terrorists. They concluded that, among violent offenders who exhibited proactive violence (a subtype of violence the authors believe to be more applicable to terrorists), there was decreased grey matter in the orbitofrontal and prefrontal cortex, and decreased volume of all temporolimbic structures and the posterior cingulate cortex. They also found reduced functional connectivity between the frontal cortex and the limbic areas, anterior insula and posterior cingulate cortex. The prefrontal cortex is responsible for executive functioning
(Yuan 2014), and the orbitofrontal cortex is a part in the prefrontal cortex responsible for behavioural inhibition (Kringelbach 2004). This finding is supported by a meta-analysis by Brower $\&$ Price (2001), which showed that people with orbitofrontal cortex lesions were more likely to demonstrate aggression and impulsiveness. The hippocampus, which is part of the limbic system, is involved in spatial memory and learning, and has implications in violence control (Kheirbek 2011). A study by Cope et al (2014) found hippocampal tissue volume to be reduced bilaterally in incarcerated adolescent male homicide offenders compared with males sentenced for other crimes.

Bogerts et al's (2018) review of violent offenders also found structural and functional abnormalities in brain regions crucial for empathy and compassion. Similar deficits have been found in individuals with antisocial personality disorder (Blair 2005; Marazziti 2013), and Marazziti (2016) has proposed that psychopathy could be a starting point for researchers trying to make sense of possible psychological profiles and features of terrorists. However, a systematic review examining studies of the mental state of terrorists found no major psychopathology, reporting that 'the evidence suggesting terrorist normality is more plentiful and of better quality' (Silke 1998).

It is important to emphasise that the data so far from neuroimaging studies are speculative and extrapolative, and more studies need to be done on terrorists rather than on violent offenders.

\section{Can mental illness account for terrorists' actions?}

Anders Breivik, who carried out a mass murder in Norway in July 2011, was found by the court to be sane and guilty of his crimes, despite being assessed by the court-appointed psychiatrists to have paranoid schizophrenia and narcissistic personality disorder. This case illustrated that a psychiatric diagnosis, even if present, does not provide motive and therefore needs to be appraised in the context of social and cultural circumstances. The psychological autopsy of Omar Mateen, who killed 49 people in a mass shooting in a gay club in Orlando, Florida in June 2016, revealed that he was emotionally unstable and had harboured seriously disturbing thoughts prior to the murders. Multiple media reports questioned his mental state and the most prevalent question that surfaced was whether he had a mental illness that accounted for his actions. Certainly, he might have had a mental illness that affected his perception of reality and emotional control, but there were also many other plausible possibilities, such as stress over challenges 
in life, hatred towards LGBT (lesbian, gay, bisexual and transgender) people or radicalisation by Islamic fundamentalists. It could even be a combination of these factors. It would be impossible to tease out the exact contributing factors unless a meticulous chronological and longitudinal history is obtained. This is often challenging for a multitude of reasons, including the death of the attacker during the attack, lack of history collaborators and complex social background.

\section{Inconsistency of findings}

Inconsistent findings in the literature have led researchers to question the validity of the postulations, the quality of the data and methodological rigour of the studies (Corner 2016). Three contributing factors have been raised.

First, the classification of 'terrorist' is often done in an aggregated and non-specific fashion, which fails to recognise unique differences between individuals. For instance, an accomplice (e.g. bomb maker) is very different from a perpetrator (e.g. bomb planter), and the profile of a group actor is likely to be different from that of a lone actor in terms of roles, expectations and experiences.

Second, mental illness has been viewed in a similarly static and dichotomous fashion, with some studies highlighting very specific disorders, such as psychopathy or personality disorders. However, we need to acknowledge that mental health problems span a continuum, from neurodevelopmental, personality and adjustment problems to severe pathological disorders, with shades of grey in between. Consequently, individuals with any particular mental illness have varying capabilities, so the long-standing notion of psychiatric patients being incapable of orchestrating a rational attack is flawed and unrealistic. Mental illness and terrorist behaviour are not mutually exclusive, and mental illness may be a by-product of terrorism rather than vice versa.

Third, it is necessary to consider factors such as social network theories, social learning, learned behaviour, behavioural psychology and situational group pressure in the analysis of terrorist behaviour (Weatherston 2003).

\section{Study limitations and obstacles to research}

In our opinion, current studies of terrorism are limited by the fact that most can only be conducted retrospectively, as many terrorists who follow through with their attacks lose their lives or go into hiding.

There have also been criticisms that terrorism research is too 'state-centric' and that there is a lack of primary research (Horgan 2008).
Inconsistent definition of terrorism and differing research methods make it problematic to compare and pool data from different studies. Research into terrorism may necessitate treacherous travel to politically unstable places (Piccinni 2018), a challenging proposition. The conflicting interests and agendas of the state and researchers remain an obstacle to conducting more robust longitudinal studies with would-be terrorists and gaining a greater understanding into their mind and behaviour. There is also a lack of research across countries, which results in restricted perspectives that might not be representative of the global picture. A review study by Jarvis (2016) found that the majority of lead authors of articles in a leading terrorism studies journal lived in the UK or the USA. A wider perspective in terrorism research and cross-collaborative efforts among researchers and security experts in different countries would allow us to better understand the intricacies and heterogeneity of terrorism and derive feasible strategies that are uniquely suited to particular societies.

\section{Future research}

The conflicting findings noted above show that researchers have not found a common psychological profile for terrorists. This is attributed to the absence of systematic and methodologically rigorous research, rather than to direct findings from studies. The most logical way forward to clarify the relationship between mental illness and terrorism would be to conduct more comparative studies of terrorists from different countries using clinical interviews and standard validated psychological tests. This would be an arduous task, but until such studies are published, the only responsible and scientifically sound conclusion is that we are not certain whether terrorists share common traits or even whether is a causal association with mental illness, although we cannot be sure that there is not (Merari 2010).

\section{Risk and threat assessments}

Considering the grave emotional and economic cost of terrorism (Quintana-Domeque 2017; Vorsina 2017), it is imperative that more focus be placed on preventing it and identifying individuals at risk of becoming terrorists. The UK's counterterrorism strategy, CONTEST, was introduced in 2003 and has undergone several revisions, with the most recent one in 2011. Prevent, one of the four 'workstreams' of this strategy, includes the counteracting of terrorist ideology and supporting those who are vulnerable to radicalisation. Since February 2015, in response to escalating terrorist activity, all National Health Service (NHS) staff have been 
obliged to undergo basic Prevent awareness training to help identify people who might be vulnerable to radicalisation and refer them to Channel, the government's 'deradicalisation' programme. Hurlow et al (2016) have supported the initiative, stating that psychiatrists have a responsibility to protect society from violence resulting from mental illness and to sieve out individuals at risk. Many psychiatrists, however, have argued against medicalising terrorism and distance themselves from the sensitive issue of racism and the sociopolitical and economic factors that drive terrorism. Many are also uncomfortable with the assessments and referral required by Prevent.

Our opinion is that all healthcare professionals have a part to play in preventing terrorism by performing risk and threat assessments, especially if the patient has any of the biopsychosocial characteristics thought to propel terrorist behaviour. In view of the nature of their work, psychiatrists are very well placed to identify individuals at risk, as they explore deeper into the patient's psychosocial problems and may unravel risk factors for terrorism.

\section{The Terrorist Radicalization Assessment Protocol (TRAP-18)}

Recent developments in threat assessment take into consideration proximal dynamically changing behavioural patterns (Meloy 2014), in addition to distal characteristics such as a history of mental disorder or criminal violence (Meloy 2016a). One example of a contemporary threat assessment tool is the Terrorist Radicalization Assessment Protocol (TRAP-18), which includes eight proximal warning behaviours and ten distal characteristics of the lone-actor terrorist (Meloy 2016a,b). It is a tool that can help clinicians to understand and manage the patient's symptoms and their specific interactions with violent behaviour, rather than merely focusing on the psychiatric diagnosis. Collateral information and monitoring of the patient's online activity on social media can also play an important part in the assessment process. The TRAP-18 can inform the clinician's professional judgement and clinical decision-making in active case management or ongoing monitoring. Its developers report a mean interrater reliability of 0.895 (range 0.69-1.0) and good discriminant validity between thwarted and successful attackers (Meloy 2018).

A retrospective study of 111 lone-actor terrorists from the USA and Europe by Meloy et al (2016b) validating the TRAP-18 found the top four warning behaviours in these terrorists to be: 'leakage' (85\%), 'pathway warning behaviour' (80\%), 'fixation' (77\%) and 'identification' (77\%). The top three distal characteristics were 'framed
BOX 3 The most common warning behaviours and distal characteristics of the TRAP-18 model

\section{Warning behaviours}

Leakage The individual communicates to a third party their intent to do harm to a target through an attack

Pathway Research, planning, preparation or implementation of an attack

Fixation An increasingly pathological preoccupation with a person or a cause that results in a deterioration in social and occupational life

Identification The individual's belief that they are an agent or soldier advancing a particular belief system

Distal characteristics

Framed by an ideology The presence of beliefs that motivate and justify the terrorist's intent, including religious and political belief

Changes in thinking and emotion The individual's thoughts and their expression become 'more strident, simplistic and absolute'; their emotions progress from 'anger and argument, to contempt and disdain for others' beliefs, to disgust for the outgroup and a willingness to homicidally aggress against them'

Failure of sexual-intimate pair bonding The individual has had no lasting sexually intimate relationship

(Meloy 2016b)

by an ideology' (100\%), 'changes in thinking and emotion' (88\%) and 'failure of sexual-intimate pair bonding' (84\%). These terms are defined in Box 3.

\section{A screening framework for mental health professionals}

In our opinion, the conceptualisation of terrorist behaviour needs to consider multiple perspectives and recognise unique individual differences, as well as roles, expectations and experiences associated with different subtypes of terrorist behaviour. On the basis of the literature we reviewed for this article, we propose a quick and simplified clinical framework of risk factors (Box 4) that can be incorporated into the clinical interview to help mental health clinicians identify high-risk patients who may be involved/are planning to be involved in terrorism. This may serve as a quick and easy screen before specific assessment tools such as the TRAP18 are used or where such tools are not immediately available (e.g. it might be necessary to buy a licence to use them or to undertake training).

\section{Social risk factors}

Social risk factors can be explored when gathering the patient's social history. A history of family 


$\begin{aligned} & \text { BOX } 4 \text { Screening list to identify high-risk } \\ & \text { patients }\end{aligned}$
Social risk factors
Family dysfunction
Friendship with radicalised individuals
Living in, or with close links to, an unstable geopolitical
area
Unemployment or underemployment
No history of romantic relationships
Clinical risk factors
Homicidal ideation
Suicidal ideation (including attempts)
Major depressive episode (in the past year)
History of violence
History of mental illness
Acts specific to terrorism
Research and plans for terrorism
Excessive fixation on political/religious/philosophical
ideology
Evidence of identification with terrorist groups

dysfunction might involve being raised by a single parent, abusive parent(s) or guardian(s) or a parent/guardian with a history of mental illness or suicide attempts. It is helpful first to explore the current relationship between the patient and their family before details about past family dynamics are explored. When asking about friendships, the clinician can explore the interests of the patient's friends to find out the kind of influences that motivate them. The clinician should also consider whether the patient is living in, or has close links to, a geopolitically unstable area, such as a country engaged in civil war, a region with widespread underemployment or unemployment (possibly affecting the patient as well) or a nation that is disaffected with its government. The clinician should also explore the patient's past romantic relationships, if any. Reisinger (2018) has postulated that sexual frustration may be a factor in the psychological make-up of a suicide terrorist, as it causes a wide range of negative emotions, including anxiety, agitation, dysphoria, loneliness and stress. Therefore, it is important to explore past and current romantic or meaningful relationships.

\section{Clinical risk factors}

Clinicians should pay attention to patients with homicidal and suicidal ideation, and those suffering a major depressive episode. However, these clinical factors are non-specific and need to be contextualised. If a patient has many social and clinical risk factors, the clinician should explore whether they have an excessive fixation on an ideology and/or an identification with terrorist groups.

\section{Acts specific to terrorism}

Finally, the clinician can explore whether the patient has done any research or formulated any plans for a terrorist attack. Enquiring about acts specific to terrorism requires particular sensitivity on the clinician's part.

\section{Caveat}

Clinicians should be mindful that the combination of factors in the context of the patient's background is the best indicator of possible risk, rather than any single factor (with the exception of acts specific to terrorism). The interview should be carried out in a non-judgmental and non-accusing manner in order to establish the rapport necessary for gathering sufficient information to make the assessment and provide effective intervention.

\section{Conclusions}

Many biopsychosocial factors contribute to terrorism, and it is probably a combination of these, rather than an isolated factor, that shapes a terrorist's behaviour. Prevention of terrorism requires a multipronged approach that involves addressing its causes - improving quality of life by enhancing socioeconomic and political stability - and detection of terrorist extremism in individuals so that timely intervention can be initiated.

Although a causative link between mental illness and terrorism is still debated, psychological problems and terrorism are likely to be related to a certain degree, and therefore careful consideration needs to be given to prevent further stigmatisation of mental illness. Cross-disciplinary collaboration is needed, with psychiatrists applying clinically valid assessment tools and interventions and referring at-risk individuals to programmes such as Channel. Nevertheless, mental health professionals should not lose sight of their ethical responsibility to protect and advocate the rights of their patients. They should also play their part in educating the public about challenges faced by people with mental illness and promoting social inclusiveness within the community.

There is a paucity of research analysing protective factors against involvement in terrorism (Gill 2017) or factors that promote community resilience to terrorism (Horgan 2017). Recent large-scale research by Choo and colleagues (Choo 2017a,b) examining risk and protective factors in (non-terrorism-related) 
MCO answers

1 d 2 e 3 a 4 e 5 e suicide among Asians uncovered the complex interplay of factors that underlie resilience and vulnerabilities, with clinical implications for outreach into vulnerable communities using a primary prevention approach. Similarly, further research into terrorist behaviour could consider the intersecting relationships between static and dynamic risk factors, as well as protective factors that could buffer against risks. Such research could inform effective counterterrorism strategies involving the collaborative efforts of psychiatrists, psychologists, other healthcare workers, government agencies and communities, in the development of evidencebased policies that are compassionate and socially inclusive without compromising national security.

\section{References}

Bazex H, Bénézech M, Mensat J-Y (2017) 'Le miroir de la haine'. La prise en charge pénitentiaire de la radicalisation : analyse clinique et criminologique de 112 personnes placées sous main de justice. Annales MédicoPsychologiques, Revue Psychiatrique, 175: 276-82.

Bhui K, James A, Wessely S (2016) Mental illness and terrorism. BMJ, 354: i4869.

Blair RJR (2005) Applying a cognitive neuroscience perspective to the disorder of psychopathy. Development and Psychopathology, 17 865-91.

Bogerts B, Schone M, Breitschuh S (2018) Brain alterations potentially associated with aggression and terrorism. CNS Spectrums, 23: 129-40.

Brower MC, Price BH (2001) Neuropsychiatry of frontal lobe dysfunction in violent and criminal behaviour: a critical review. Journal of Neurology, Neurosurgery, and Psychiatry, 71: 720-6.

Campelo N, Oppetit A, Neau F, et al (2018) Who are the European youths willing to engage in radicalisation? A multidisciplinary review of their psychological and social profiles. European Psychiatry, 52: 1-14.

Choo CC, Harris KM, Ho RC (2017a) Prediction of lethality in suicide attempts: gender matters. OMEGA - Journal of Death and Dying, 22 Aug: doi 10.1177/0030222817725182 [Epub ahead of print].

Choo CC, Harris KM, Peter KHC, et al (2017b) Does ethnicity matter in risk and protective factors for suicide attempts and suicide lethality? PLoS One, 12(4): e0175752.

Cope LM, Ermer E, Gaudet LM, et al (2014) Abnormal brain structure in youth who commit homicide. Neurolmage: Clinical, 4: 800-7.

Corner E, Gill P (2015) A false dichotomy? Mental illness and lone-actor terrorism. Law and Human Behavior, 39: 23-34.

Corner E, Gill P, Mason 0 (2016) Mental health disorders and the terrorist: a research note probing selection effects and disorder prevalence. Studies in Conflict \& Terrorism, 39: 560-8.

Gadarian SK (2010) The politics of threat: how terrorism news shapes foreign policy attitudes. Journal of Politics, 72: 469-83.

Gill P, Corner $E$ (2017) There and back again: the study of mental disorder and terrorist involvement. American Psychologist, 72: 231-41.

Horgan J, Boyle MJ (2008) A case against 'critical terrorism studies'. Critical Studies on Terrorism, 1: 51-64.

Horgan JG (2017) Psychology of terrorism: introduction to the special issue. American Psychologist, 72: 199-204.

Horowitz MC (2015) The rise and spread of suicide bombing. Annual Review of Political Science, 18: 69-84.

Hurlow J, Wilson S, James DV (2016) Protesting loudly about Prevent is popular but is it informed and sensible? BJPsych Bulletin, 40: 162-3.
Jarvis L (2016) Critical terrorism studies after 9/11. In Routledge Handbook of Critical Terrorism Studies (ed R Jackson): 28-38. Routledge.

Kheirbek MA, Hen R (2011) Dorsal vs ventral hippocampal neurogenesis: implications for cognition and mood. Neuropsychopharmacology, 36: 373-4.

Kringelbach ML, Rolls ET (2004) The functional neuroanatomy of the human orbitofrontal cortex: evidence from neuroimaging and neuropsychology. Progress in Neurobiology, 72: 341-72.

Kydd AH, Walter BF (2006) The strategies of terrorism. International Security, 31: 49-80.

LaFree G, Gruenewald J (2018) The intersection of homicide, terrorism, and violent extremism. Homicide Studies, 22: 3-7.

Lankford A (2014) Précis of The Myth of Martyrdom: What Really Drives Suicide Bombers, Rampage Shooters, and Other Self-Destructive Killers. Behavioral and Brain Sciences, 37: 351-62.

Liem M, van Buuren J, de Roy van Zuijdewijn J, et al (2018) European lone actor terrorists versus 'common' homicide offenders: an empirical analysis. Homicide Studies, 22: 45-69.

Marazziti D, Baroni S, Landi P, et al (2013) The neurobiology of moral sense: facts or hypotheses? Annals of General Psychiatry, 12: 6.

Marazziti D (2016) Psychiatry and terrorism: exploring the unacceptable. CNS Spectrums, 21: 128-30.

Meloy JR, Hart SD, Hoffmann J (2014) Threat assessment and threat management. In International Handbook of Threat Assessment (eds JR Meloy, J Hoffmann): 3-17. Oxford University Press.

Meloy JR, Genzman J (2016a) The clinical threat assessment of the lone-actor terrorist. Psychiatric Clinics of North America, 39: 649-62.

Meloy JR, Gill P (2016b) The lone-actor terrorist and the TRAP-18. Journal of Threat Assessment and Management, 3: 37-52.

Meloy JR (2018) The operational development and empirical testing of the Terrorist Radicalization Assessment Protocol (TRAP-18). Journal of Personality Assessment, Jun 21: doi 10.1080/00223891.2018.1481077 [Epub ahead of print].

Merari A, Diamant I, Bibi A, et al (2009) Personality characteristics of 'self martyrs'/'suicide bombers' and organizers of suicide attacks. Terrorism and Political Violence, 22: 87-101.

Merari A (2010) Driven to Death: Psychological and Social Aspects of Suicide Terrorism. Oxford University Press.

Moller-Leimkuhler AM (2018) Why is terrorism a man's business? CNS Spectrums, 23: 119-28.

Piccinni A, Marazziti D, Veltri A (2018) Psychopathology of terrorists. CNS Spectrums, 23: 141-4

Pollitt MM (1997) Cyberterrorism: fact or fancy? Proceedings of the 20th National Information Systems Security Conference, October: 285-9.

Quintana-Domeque C, Ródenas-Serrano P (2017) The hidden costs of terrorism: the effects on health at birth. Journal of Health Economics, 56 : 47-60.

Reisinger M (2018) Addiction to death. CNS Spectrums, 23: 166-9.

Seger KA (2003) Deterring terrorists. In Terrorists, Victims and Society: Psychological Perspectives on Terrorism and its Consequences (ed A Silke): 257-70. John Wiley \& Sons.

Silke A (1998) Cheshire-cat logic: the recurring theme of terrorist abnormality in psychological research. Psychology, Crime \& Law, 4: $51-69$

Smith M, Zeigler SM (2017) Terrorism before and after 9/11 - a more dangerous world? Research \& Politics, 4(4): 2053168017739757.

Speckhard A (2007) The emergence of female suicide terrorists. Studies in Conflict \& Terrorism, 31: 995-1023.

Stoddard FJ Jr, Gold J, Henderson SW, et al (2011) Psychiatry and terrorism. Journal of Nervous and Mental Disease, 199: 537-43.

Tarlow P (2017) The interaction of religion and terrorism. International Journal of Safety and Security in Tourism/Hospitality, 16: paper 2. 
Vorsina M, Manning M, Fleming CM, et al (2017) The welfare cost of terrorism. Terrorism and Political Violence, 29: 1066-21.

Weatherston D, Moran J (2003) Terrorism and mental illness: is there a relationship? International Journal of Offender Therapy and Comparative Criminology, 47: 698-713.

Weimann G (2005) Cyberterrorism: the sum of all fears? Studies in Conflict \& Terrorism, 28: 129-49.
Yuan P, Raz N (2014) Prefrontal cortex and executive functions in healthy adults: a meta-analysis of structural neuroimaging studies. Neuroscience and Biobehavioral Reviews, 42: 180-92.

Zimbardo PG (2004) A situationist perspective on the psychology of evil: understanding how good people are transformed into perpetrators. In The Social Psychology of Good and Evil (ed AG Miller): 21-50. Guilford Press.

\section{MCQs}

Select the single best option for each question stem

1 Which of the following is not a social risk factor for terrorist behaviour?

a emotional abuse in childhood

b no meaningful relationship with anyone

c parental neglect

d substance misuse

e unemployment.

2 The inconsistency of findings in terrorism research can be explained by:

a different definitions of terrorism

b mainly retrospective studies

c small samples d studies from only a few countries

e all of the above.

3 Which of the following is not a warning indicator of terrorism in the TRAP-18?

a excitability

b failure of sexual-intimate pair bonding

c fixation

d identification

e leakage.

4 Brain areas implicated in violence include:

a anterior insula

b hippocampus

c orbitofrontal cortex d posterior cingulate cortex

e all of the above.

5 When a new patient presents in clinic with low mood and verbalises extremist thinking, which of the following would you not do?

a assess for antisocial personality traits

b explore childhood history

c explore for family history of mental illness

d explore for fixation on particular philosophical ideology

e refer the patient to Channel immediately. 